\title{
Human immunodeficiency virus-negative plasmablastic lymphoma: A comprehensive analysis of 114 cases
}

\author{
MIN LIU $^{1 *}$, BAILONG LIU ${ }^{1 *}$, BIN LIU $^{2}$, QIANG WANG $^{1}$, LIJUAN DING $^{1}$, \\ CHENGCHENG XIA $^{1}$ and LIHUA DONG ${ }^{1}$ \\ Departments of ${ }^{1}$ Radiation Oncology and ${ }^{2}$ Hand Surgery, The First Hospital, \\ Jilin University, Changchun, Jilin 130021, P.R. China
}

Received November 10, 2014; Accepted January 22, 2015

DOI: $10.3892 /$ or.2015.3808

\begin{abstract}
Human immunodeficiency virus-negative plasmablastic lymphoma (PBL) is an extremely rare entity. Its clinicopathological features, optimal treatment strategy and prognostic factors remain obsure. An extensive search was performed in the English language literature within the Pubmed database using the key words: 'plasmablastic lymphoma and human immunodeficiency virus-negative or immunocompetent'. Data from 114 patients from 52 articles were analyzed. The mean patient age at diagnosis was 58.90 years (range, 2-86). HIV-negative PBL showed a predilection for elderly individuals (patients older than 60 years, 56.14\%) and affected more males than females (M:F, 2.29:1). Ann Arbor stage IV patients accounted for $39.22 \%$ while bone marrow involvement was less frequent (12.79\%). The Ki-67 index was high with a mean expression of $83 \%$. Epstein-Barr virus (EBV) infection was common being positive in $58.70 \%$ of the patients while herpesvirus- 8 (HHV-8) infection was rare being positive in only $7.55 \%$ of the patients. Immunosuppression was noted in $28.16 \%$ of patients. The median overall survival (OS) was 19 months. The 1- and 2-year survival rates were 52.3 and $45.3 \%$, respectively. Age, gender and primary site showed no strong relationship with OS while Immunosuppression, Ann Arbor stage IV and EBV negativity were able to predict a poorer OS. Either complete remission (CR) or partial remis-
\end{abstract}

Correspondence to: Dr Lihua Dong, Department of Radiation Oncology, The First Hospital, Jilin University, 71 Xinmin Street, Changchun, Jilin 130021, P.R China

E-mail: lijie200461@126.com

*Contributed equally

Abbreviations: CR, complete remission; EBV, Epstein-Barr virus; HHV-8, herpesvirus-8; HIV, human immunodeficiency virus; OS, overall survival; PBL, plasmablastic lymphoma; PR, partial remission

Key words: clinicopathological features, plasmablastic lymphoma, HIV negative, etiology, treatment, prognosis sion $(\mathrm{PR})$ was superior to the refractory group in $\mathrm{OS}(\mathrm{P}<0.0001$ and $\mathrm{P}=0.0066$, respectively). For stage I patients, the application of radiotherapy did not improve the OS. In conclusion, HIV-negative PBL is a distinct entity likely occurring in elderly and immunosuppressed individuals. Immunosuppression status, Ann Arbor stage IV, EBV negativity and refractory to treatment are poor prognostic factors of OS in HIV-negative PBL.

\section{Introduction}

Plasmablastic lymphoma (PBL) was firstly identified as a unique clinicopathological entity by Delecluse et al (1). For a long time, PBL was viewed as a disease exclusively involving the oral sites of human immunodeficiency virus-positive individuals. Recently, more and more cases of PBL in immunocompetent patients have been reported. However, there is little consensus concerning many aspects such as etiology, clinical findings, optimal treatment strategy and prognostic factors of HIV-negative PBL. Furthermore, Castillo et al demonstrated that HIV-negative PBL cases are rather different compared with their counterparts (2). Through an extensive literature search, 114 cases of HIV-negative PBL were described. To our knowledge, this is the most comprehensive analysis concerning PBL in HIV-negative patients. Our study provides a full-scale view and helps to expand our understanding of this unique lymphoma.

\section{Patients and methods}

Literature review. An extensive search was carried out in Pubmed using the key words: 'plasmablastic lymphoma and human immunodeficiency virus-negative or immunocompetent' in the English language literature. Only cases with definite pathologic diagnosis of PBL and description of no HIV infection were enrolled. A total of 114 cases of HIV-negative PBL were described in case reports or in small sample size case analyses between February 1997 and 2014 (1,3-53).

Data retrieval. Data were retrieved according to characteristics such as age, gender, stage, site, bone marrow involvement, Ki-67 expression, pathological findings, Epstein-Barr virus (EBV) infection, herpesvirus-8 (HHV-8) infection, immunosuppression, treatment strategy (chemotherapy, radiotherapy 
Table I. Clinical features of the HIV-negative PBL cases.

\begin{tabular}{|c|c|c|}
\hline Features & $\mathrm{n}$ & $\%$ \\
\hline \multicolumn{3}{|l|}{ Age (years) $(n=114)$} \\
\hline Mean at diagnosis & \multicolumn{2}{|c|}{58.90} \\
\hline Range & \multicolumn{2}{|c|}{$2-86$} \\
\hline$<30$ & 7 & 6.14 \\
\hline $30-60$ & 43 & 37.72 \\
\hline$\geq 60$ & 64 & 56.14 \\
\hline \multicolumn{3}{|l|}{ Gender $(n=114)$} \\
\hline Male & 79 & 69.30 \\
\hline Female & 35 & 30.70 \\
\hline \multicolumn{3}{|l|}{ Ann Arbor stage $(n=102)$} \\
\hline I & 32 & 31.37 \\
\hline II & 18 & 17.65 \\
\hline III & 12 & 11.76 \\
\hline IV & 40 & 39.22 \\
\hline \multicolumn{3}{|c|}{ Bone marrow involvement $(n=86)$} \\
\hline With involvement & 11 & 12.79 \\
\hline No involvement & 75 & 87.21 \\
\hline \multicolumn{3}{|l|}{ Primary sites $(n=114)$} \\
\hline LN & 23 & 20.18 \\
\hline Extra LN & 91 & 79.82 \\
\hline Oral & 20 & 17.54 \\
\hline Nasal cavity and sinus & 20 & 17.54 \\
\hline Gastrointestinal tract & 18 & 15.79 \\
\hline Skin & 7 & 6.14 \\
\hline Other extranodal sites & 26 & 22.81 \\
\hline
\end{tabular}

HIV, human immunodeficiency virus; PBL, plasmablastic lymphoma; LN, lymph node.

and surgery), treatment response, survival and prognosis. Chemotherapy included treatment with bortezomib, but excluded treatment merely with steroids. Surgery excluded incisional biopsy. Ki-67 expression with exact values was recruited, and data showing values of $1+, 2+, 3+$ and $4+$ were excluded. Immunohistochemistry (IHC) with \pm was viewed as positive expression. Complete remission (CR) included near $\mathrm{CR}$. The period from diagnosis to death or latest follow-up was considered as overall survival (OS).

Statistical analysis. Cumulative survival was expressed by Kaplan-Meier estimates and compared with the log-rank (Mantel-Cox) test. SPSS 15.0 statistical software was used for data analysis. P-value $<0.05$ was indicative of a statistically significant result.

\section{Results}

Clinical features. HIV-negative PBL occurred in a wide spectrum of patients, aged from 2 to 86 years, with a mean age at diagnosis of 58.90 years. Notably, HIV-negative PBL mostly occurred in the elderly population. As Table I shows, patients older than 60 years accounted for $56.14 \%$ of all the
Table II. Etiological analysis of HIV-negative PBL cases.

\begin{tabular}{lrr}
\hline Etiology & $\mathrm{n}$ & $\%$ \\
\hline EBV infection (n=92) & & \\
With EBV infection & 54 & 58.70 \\
Without EBV infection & 38 & 41.30 \\
Immunosuppression (n=103) & & \\
No immunosuppression & 74 & 71.84 \\
With immunosuppression & 29 & 28.16 \\
Post transplantation & 11 & 10.68 \\
Immune-related disease & 8 & 7.77 \\
Current or previous malignancy & 10 & 9.71 \\
Herpesvirus-8 (HHV-8) (n=53) & & \\
With HHV-8 infection & 4 & 7.55 \\
Without HHV-8 infection & 49 & 92.45 \\
\hline
\end{tabular}

HIV, human immunodeficiency virus; PBL, plasmablastic lymphoma; EBV, Epstein-Barr virus; HHV-8, herpesvirus-8.

cases. PBL was rarely present in young immunocompetent individuals especially children and teenagers (only 3 patients). HIV-negative PBL was more common in males with a maleto-female ratio of 2.29. With respect to clinical stage, stage IV was most common and I was secondary. Although stage IV was noted in $39.22 \%$ of the patients, bone marrow involvement was present in only $12.79 \%$ patients. As far as the primary site was concerned, the majority was extranodal. The oral cavity, nasal cavity and sinus were 2 most common sites of involvement. A total of $15.79 \%$ of the cases involved the gastrointestinal tract.

Etiological analysis. As shown in Table II, EBV infection was common in HIV-negative PBL, involving $58.70 \%$ of the patients, while HHV-8 infection was rather rare, being positive in only 4 cases. Immunosuppression status including post-transplantation, immune-related disease and current or previous malignancy was noted in quite a number of patients $(28.16 \%)$.

Pathological findings. As shown in Table III, plasma cell markers CD38, VS38c, CD138 and MUM1 were expressed universally in PBL without HIV infection. EMA and CD45 were variably expressed, being positive in 59.26 and $40 \%$ of the cases, respectively. B-cell marker CD20 was rarely noted (only 1 case,+ 4 cases \pm ). A total of $37.93 \%$ of the cases had CD79a expression. Notably, a small number of cases expressed T-cell markers CD3 and CD5; 14.89 and 13.04\%, respectively. Furthermore, a high number of patients $(21.43 \%)$ expressed NK-cell marker CD56. Ki-67 expression was universally high with a mean value of $83 \%$, indicating an aggressive behavior.

Treatment and prognosis. As Table IV demonstrates, 18.52\% of the patients underwent surgery. A total of $34.44 \%$ of the patients received radiotherapy. A majority of the patients (84.27\%) received chemotherapy. The CR, partial remission (PR) and refractory rates were 54.93, 16.90 and $25.35 \%$, respectively. 
Table III. Pathological findings of the HIV-negative PBL cases.

\begin{tabular}{lcr}
\hline & $\begin{array}{c}\text { Positive/total } \\
\text { tested cases }\end{array}$ & $\%$ \\
\hline Plasma cell markers & & \\
CD38 & $22 / 32$ & 68.75 \\
CD138 & $67 / 82$ & 81.71 \\
VS38c & $11 / 11$ & 100.00 \\
MUM1 & $47 / 57$ & 82.46 \\
Leukocyte common & & \\
antigen & & 40.00 \\
CD45 & $18 / 45$ & 5.75 \\
B-cell markers & & 37.93 \\
CD20 & $5 / 87(4 \pm, 1+)$ & \\
CD79a & $22 / 58$ & 14.89 \\
T-cell markers & & 13.04 \\
CD3 & $7 / 47$ & \\
CD5 & $3 / 23$ & 21.43 \\
NK-cell markers & & \\
CD56 & $9 / 42$ & \\
Epithelial membrane & & \\
antigen & & \\
EMA & & \\
Ki-67 & & \\
\hline
\end{tabular}

HIV, human immunodeficiency virus; PBL, plasmablastic lymphoma; IHC, immunohistochemistry.

Table IV. Treatment strategies, response and prognosis of the HIV-negative PBL cases.

\begin{tabular}{lcc}
\hline Treatment strategy & $\mathrm{n}$ & $\%$ \\
\hline Surgery (n=81) & & \\
Received Surgery & 15 & 18.52 \\
No surgery & 66 & 81.48 \\
Radiotherapy (n=90) & & \\
Received radiotherapy & 31 & 34.44 \\
No radiotherapy & 59 & 65.56 \\
Chemotherapy (n=89) & & \\
Received chemotherapy & 75 & 84.27 \\
No chemotherapy & 14 & 15.73 \\
Treatment response (n=71) & & \\
CR & 39 & 54.93 \\
PR & 12 & 16.90 \\
Refractory & 18 & 25.35 \\
Intolerance & 2 & 2.82 \\
Prognosis (n=96) & & \\
Alive & 50 & 47.92 \\
Dead & 46 & \\
\hline
\end{tabular}

HIV, human immunodeficiency virus; PBL, plasmablastic lymphoma; $\mathrm{CR}$, complete remission; $\mathrm{PR}$, partial remission.

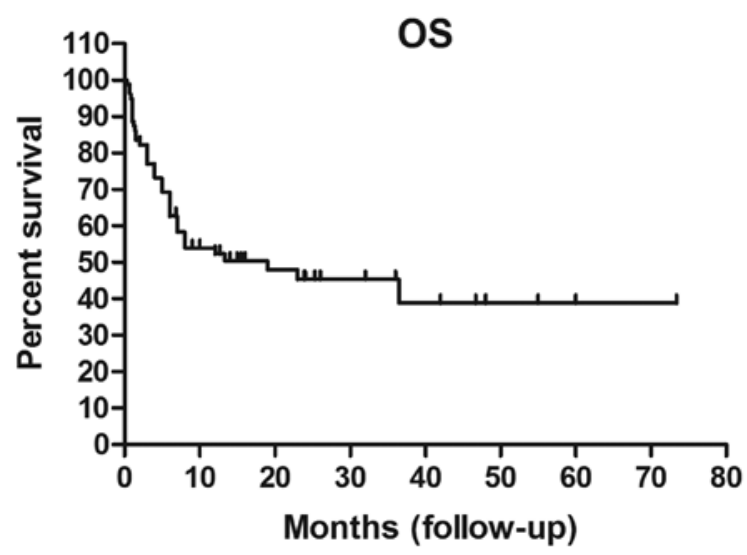

Figure 1. Overall survival (OS) curve $(n=80)$.

Prognostic factors of OS. As shown in Fig. 1, the median OS was 19 months. The 1- and 2-year survival rates were 52.3 and $45.3 \%$, respectively.

Immunosuppression was a poor prognostic factor of OS. As Fig. 2A demonstrates, patients without immunosuppression had an apparently better OS than their immunosuppression counterpart with a median survival of 36.5 vs. 6.5 months. As far as Ann Arbor stage was concerned, stage I showed an OS advantage over stage IV ( $\mathrm{P}=0.0079$, Fig. 2B). EBV negativity was another poor prognostic factor of OS. As Fig. 2C shows, HIV negative PBL patients without EBV infection had a much poorer OS than EBV positive patients $(\mathrm{P}=0.0046)$.

Treatment response had a strong association with OS. As shown in Fig. 3, either CR or PR was superior to the refractory group in $\mathrm{OS}(\mathrm{P}<0.0001$ and $\mathrm{P}=0.0066$, respectively). Furthermore, the CR group showed an OS benefit when compared with PR $(\mathrm{P}=0.001)$.

Univariate analysis (Table V) revealed that age, gender and primary site had no strong relationship with OS. Ann Arbor stage IV, immunosuppression, EBV negativity and refractory to treatment were poor prognostic factors of OS. For stage I patients, the application of radiotherapy did not improve the OS.

\section{Discussion}

In 1997, Delecluse et al first described 16 PBL cases (15 HIV-positive and $1 \mathrm{HIV}$-negative) (1). PBL was once considered as a malignancy that predominantly occurred in HIV-infected individuals. In 2010, Castillo et al analyzed 71 cases of HIV-negative PBL published before August 2009 and first revealed that HIV-negative PBL had distinct clinicopathological features (2). Soon after, Castillo et al (54) and Liu et al (26) reviewed 76 and 79 cases of HIV-negative PBL published before June 2010. In recent years, with increasing awareness of this unique entity, more cases have been reported in diverse sites in patients without HIV infection. Thus, it is necessary for us to retrieve all the cases published to date to get a full-scale understanding of this unique lymphoma.

With respect to clinicopathological features of HIV-negative PBL, Ann Arbor stage I was rather predominant, accounting for $31.37 \%$ of the entire enrollment, higher than a previous study by Castillo et al (2) (23\%), and similar to a study by 
A

os
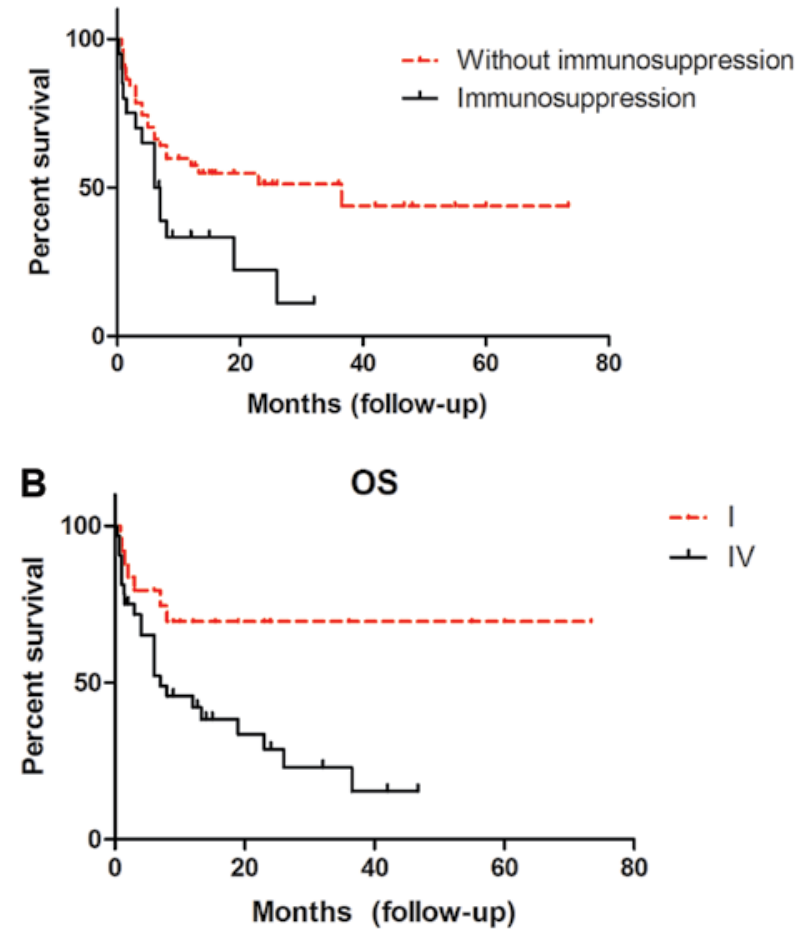

C

OS

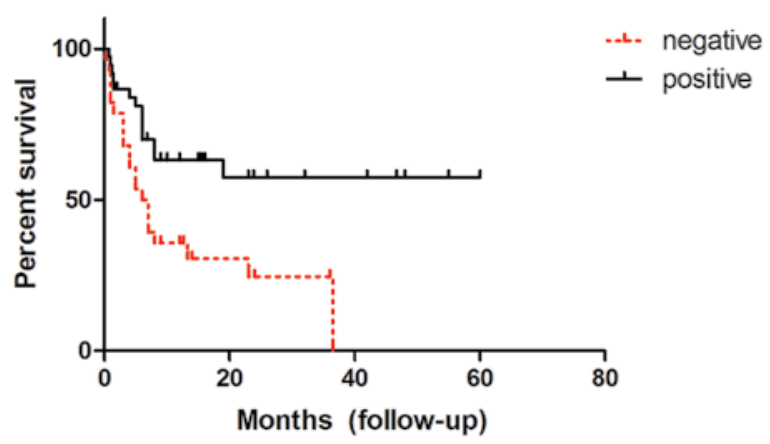

Figure 2. Immune status, Ann Arbor stage and EBV infection status affect overall survival (OS) (hazard ratio, 0.4114, $\mathrm{P}=0.0223$; hazard ratio, 0.3731, $\mathrm{P}=0.0079$; hazard ratio, 2.763, $\mathrm{P}=0.0046$, respectively).

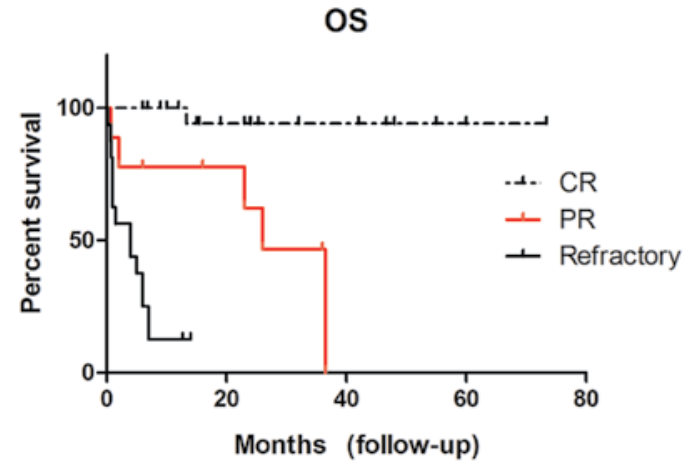

Figure 3. Treatment response had a strong association with overall survival (OS).

Liu et al (26) (32.9\%). Furthermore, stage I showed a OS superiority than stage IV $(\mathrm{P}=0.0079)$. Primary skin HIV-negative PBL accounted for a smaller proportion, only $6.14 \%$, when compared with a previous study of $12 \%$ (54). More patients (18.52\%) received surgery. Castillo et al reported that only $4 \%$ of the patients underwent surgery (54). CD56 expression in our research was $21.43 \%$, much higher than Castillo et al findings (6\%) (2). Furthermore, a portion of HIV-negative PBL expressed T-cell markers such as CD3 (14.89\%) and CD5 (13.04\%).

Regarding the aspect of etiology, some studies have indicated that PBL is closely related with EBV infection (55). Our study also confirmed that $58.70 \%$ cases of HIV-negative PBL exhibited EBV infection. Furthermore, univariate analysis showed that EBV infection was a good prognostic factor of OS $(\mathrm{P}=0.0046)$. The concrete mechanism need to be clarified in the future. Furthermore, only $7.55 \%$ of patients were HHV-8positive, indicating that HHV-8 infection has a negligible role in HIV-negative PBL. On the contrary, we found that immunosuppression contributed to $28.16 \%$ of the cases including post-transplantation, immune-related disease and current or previous malignancy. Additionally, immunosuppression was a poor prognostic factor for OS. Patients with immunosuppression had a poorer OS with a median survival of 6.5 months

Table V. Univariate analysis of prognostic factors for OS.

\begin{tabular}{lcr}
\hline & Hazard ratio (95\% CI) & P-value \\
\hline Age ( $\geq 60$ vs. $<60)$ & $1.195(0.6367-2.243)$ & 0.5792 \\
Gender (M vs. F) & $0.8231(0.4275-1.585)$ & 0.5604 \\
Primary site (oral vs. extraoral) & $0.6241(0.2646-1.472)$ & 0.2816 \\
Ann Arbor stage (I vs. IV) & $0.3731(0.1802-0.7727)$ & 0.0079 \\
Immunosuppression (with vs. without) & $0.4114(0.1920-0.8815)$ & 0.0223 \\
EBV (infection vs. no infection) & $2.763(1.368-5.578)$ & 0.0046 \\
Stage I (with radiotherapy vs. without) & $0.7052(0.1484-3.351)$ & 0.6604 \\
Treatment response (CR vs. refractory) & $0.01804(0.005324-0.06111)$ & $<0.0001$ \\
Treatment response (PR vs. refractory) & $0.2402(0.08593-0.6716)$ & 0.0066 \\
Treatment response (CR vs. PR) & $0.04391(0.006841-0.2819)$ & 0.001 \\
\hline
\end{tabular}

OS, overall survival; HIV, human immunodeficiency virus; PBL, plasmablastic lymphoma; EBV, Epstein-Barr virus; CR, complete remission; PR, partial remission. 
while patients without immunosuppression achieved a median survival of 36.5 months. Our data also showed that HIV-negative PBL had a predilection for elderly individuals (patients older than 60 years, 56.14\%). This proportion in our research was higher than that noted in the studies of Liu et al (43\%) (26) and Castillo et al (49\%) (54). Elderly individuals often have immune senescence. Decline in immune function may be critical in the disease evolution of HIV-negative PBL.

Since PBL without HIV infection usually has a poorer response to chemotherapy compared with HIV-positive counterparts (2), there is urgent need to develop novel therapies to improve treatment efficacy. Immunotherapy may be promising.

For stage I patients, we first explored the role of radiotherapy. However, the application of radiotherapy did not improve the OS.

In our research, statistical analysis revealed that treatment response had a defined correlation with OS. Either CR or PR was superior to the refractory group in $\mathrm{OS}(\mathrm{P}<0.0001$ and $\mathrm{P}=0.0066$, respectively). Furthermore, the $\mathrm{CR}$ group showed an OS benefit when compared to PR $(\mathrm{P}=0.001)$. Castillo et al (54) demonstrated that CR to chemotherapy had increased OS when compared with patients without CR. Differently, our data elucidated that not only $\mathrm{CR}$, but PR also could bring an OS benefit. The different treatment response was derived from tumor heterogeneity. Extensive research on the heterogeneity of HIV-negative PBL may find the causes of treatment resistance and contribute to the improvement of OS.

\section{References}

1. Delecluse HJ, Anagnostopoulos I, Dallenbach F, et al: Plasmablastic lymphomas of the oral cavity: a new entity associated with the human immunodeficiency virus infection. Blood 89: 1413-1420, 1997.

2. Castillo JJ, Winer ES, Stachurski D, et al: Clinical and pathological differences between human immunodeficiency virus-positive and human immunodeficiency virus-negative patients with plasmablastic lymphoma. Leuk Lymphoma 51: 2047-2053, 2010.

3. Hatanaka K, Nakamura N, Kishimoto K, Sugino K and Uekusa T: Plasmablastic lymphoma of the cecum: report of a case with cytologic findings. Diagn Cytopathol 39: 297-300, 2011.

4. Tille JC, Pelte MF, Schwartz J, Dietrich PY and McKee TA: Plasmablastic lymphoma clinically presenting in the urinary tract. Ann Diagn Pathol 16: 219-223, 2012.

5. Takeuchi M, Ogawa F, Onishi T and Moriyama Y: Plasmablastic lymphoma in an elderly immunocompetent patient. Pathol Int 62: 347-350, 2012.

6. Mihaljevic BS, Todorovic MR, Andjelic BM, Antic DA and Perunicic Jovanovic MD: Unusual presentation of gastric plasmablastic lymphoma in HIV-negative patient. Med Oncol 29: 1186-1189, 2012.

7. Zhang LY, Lin HY, Gao LX, et al: Primary central nervous system plasmablastic lymphoma presenting in human immunodeficiency virus-negative but Epstein-Barr virus-positive patient: a case report. Diagn Pathol 7: 51, 2012.

8. Lipstein M, O'Connor O, Montanari F, Paoluzzi L, Bongero D and Bhagat G: Bortezomib-induced tumor lysis syndrome in a patient with HIV-negative plasmablastic lymphoma. Clin Lymphoma Myeloma Leuk 10: E43-E46, 2010.

9. Khurana A and Jalpota Y: Plasmablastic lymphoma in a human immunodeficiency virus negative patient. Indian J Pathol Microbiol 53: 368-369, 2010.

10. Heiser D, Müller H, Kempf W, Eisendle K and Zelger B: Primary cutaneous plasmablastic lymphoma of the lower leg in an HIV-negative patient. J Am Acad Dermatol 67: e202-e205, 2012.

11. Wang HW, Yang W, Sun JZ, Lu JY, Li M and Sun L: Plasmablastic lymphoma of the small intestine: Case report and literature review. World J Gastroenterol 18: 6677-6681, 2012.
12. Tani J, Miyoshi H, Nomura T, et al: A case of plasmablastic lymphoma of the liver without human immunodeficiency virus infection. World J Gastroenterol 19: 6299-6303, 2013.

13. Brahmania M, Sylwesterowic T and Leitch H: Plasmablastic lymphoma in the ano-rectal junction presenting in an immunocompetent man: a case report. J Med Case Rep 5: 168, 2011.

14. Nguyen DD, Loo BW Jr, Tillman G, et al: Plasmablastic lymphoma presenting in a human immunodeficiency virus-negative patient: a case report. Ann Hematol 82: 521-525, 2003.

15. Lin F, Zhang K, Quiery AT Jr, Prichard J and Schuerch C: Plasmablastic lymphoma of the cervical lymph nodes in a human immunodeficiency virus-negative patient a case report and review of the literature. Arch Pathol Lab Med 128: 581-584, 2004.

16. Tzankov A, Brunhuber T, Gschwendtner A and Brunner A: Incidental oral plasmablastic lymphoma with aberrant expression of CD4 in an elderly HIV-negative patient: how a gingival polyp can cause confusion. Histopathology 46: 348-350, 2005.

17. Scheper MA, Nikitakis NG, Fernandes R, Gocke CD, Ord RA and Sauk JJ: Oral plasmablastic lymphoma in an HIV-negative patient: A case report and review of the literature. Oral Surg Oral Med Oral Pathol Oral Radiol Endod 100: 198-206, 2005.

18. Masgala A, Christopoulos C, Giannakou N, Boukis H, Papadaki T and Anevlavis E: Plasmablastic lymphoma of visceral cranium, cervix and thorax in an HIV-negative woman. Ann Hematol 86: 615-618, 2007.

19. Hashimoto $\mathrm{M}$, Inaguma $\mathrm{S}$, Kasai K, et al: Plasmablastic lymphoma of the stomach in an HIV-negative patient. Pathol Int 62: 763-770, 2012.

20. Guan B, Zhang X, Hu W, et al: Plasmablastic lymphoma of the oral cavity in an HIV-negative patient. Ann Diagn Pathol 15: 436-440, 2011.

21. Mansoor M, Alani FS, Aslam MB, Kumar SN, Sahasrabudhe N and Khan D: A case report of cecal plasmablastic lymphoma in a HIV-negative patient. Eur J Gastroenterol Hepatol 24: 332-335, 2012.

22. Matsuki E, Miyakawa Y, Asakawa S, et al: Identification of loss of p16 expression and upregulation of MDR-1 as genetic events resulting from two novel chromosomal translocations found in a plasmablastic lymphoma of the uterus. Clin Cancer Res 17: 2101-2109, 2011.

23. Saraceni C, Agostino N, Cornfield DB and Gupta R: Plasmablastic lymphoma of the maxillary sinus in an HIV-negative patient: a case report and literature review. Springerplus 2: 142, 2013.

24. Marques I, Lagos A and Costa-Neves B: Gastric plasmablastic lymphoma in HIV-negative patient. Rev Esp Enferm Dig 105: 166-167, 2013.

25. Choi SY, Cho YA, Hong SD, Lee JI, Hong SP and Yoon HJ: Plasmablastic lymphoma of the oral cavity in a human immunodeficiency virus-negative patient: a case report with literature review. Oral Surg Oral Med Oral Pathol Oral Radiol 117: e115-e120, 2014.

26. Liu JJ, Zhang L, Ayala E, et al: Human immunodeficiency virus (HIV)-negative plasmablastic lymphoma: a single institutional experience and literature review. Leuk Res 35: 1571-1577, 2011.

27. Kim JE, Kim YA, Kim WY, et al: Human immunodeficiency virus-negative plasmablastic lymphoma in Korea. Leuk Lymphoma 50: 582-587, 2009.

28. Qing X, Sun N, Chang E, French S, Ji P and Yue C: Plasmablastic lymphoma may occur as a high-grade transformation from plasmacytoma. Exp Mol Pathol 90: 85-90, 2011.

29. Suzuki Y, Yoshida T, Nakamura N, et al: CD3- and CD4-positive plasmablastic lymphoma: a literature review of Japanese plasmablastic lymphoma cases. Intern Med 49: 1801-1805, 2010.

30. Tiong IS, Strauss M, Lau MB and Chiruka S: Cutaneous plasmablastic lymphoma in an immunocompetent patient with long-term pyrimethamine use for essential thrombocythemia: a case report and literature review. Case Rep Hematol 2013: 541783,2013

31. Gogia A and Bakhshi S: Plasmablastic lymphoma of oral cavity in a HIV-negative child. Pediatr Blood Cancer 55: 390-391, 2010.

32. McGlaughlin KL, Bajel A and Mow CD: A case of plasmablastic lymphoma harbouring an IgH/MYC translocation in a HIV negative individual. Pathology 42: 697-699, 2010.

33. Cha JM, Lee JI, Joo KR, et al: A case report with plasmablastic lymphoma of the jejunum. J Korean Med Sci 25: 496-500, 2010.

34. Teruya-Feldstein J, Chiao E, Filippa DA, et al: CD20-negative large-cell lymphoma with plasmablastic features: a clinically heterogenous spectrum in both HIV-positive and -negative patients. Ann Oncol 15: 1673-1679, 2004. 
35. Colomo L, Loong F, Rives S, et al: Diffuse large B-cell lymphomas with plasmablastic differentiation represent a heterogeneous group of disease entities. Am J Surg Pathol 28: 736-747, 2004.

36. Borenstein J, Pezzella F and Gatter KC: Plasmablastic lymphomas may occur as post-transplant lymphoproliferative disorders. Histopathology 51: 774-777, 2007.

37. Takahashi Y, Saiga I, Fukushima J, et al: Plasmablastic lymphoma of the retroperitoneum in an HIV-negative patient. Pathol Int 59: 868-873, 2009.

38. Liu F, Asano N, Tatematsu A, et al: Plasmablastic lymphoma of the elderly: a clinicopathological comparison with age-related Epstein-Barr virus-associated B cell lymphoproliferative disorder. Histopathology 61: 1183-1197, 2012.

39. Redmond M, Quinn J, Murphy P, Patchett S and Leader M: Plasmablastic lymphoma presenting as a paravertebral mass in a patient with Crohn's disease after immunosuppressive therapy. J Clin Pathol 60: 80-81, 2007.

40. Verma S, Nuovo GJ, Porcu P, Baiocchi RA, Crowson AN and Magro CM: Epstein-Barr virus- and human herpesvirus 8-associated primary cutaneous plasmablastic lymphoma in the setting of renal transplantation. J Cutan Pathol 32: 35-39, 2005.

41. Rao DD, Aggarwal N, Anehosur V, Doddihal H, Shiraganvi M and Gopalkrishnan K: Plasmablastic lymphoma of the oral cavity in immunocompetent patients: report of two cases. Int J Oral Maxillofac Surg 39: 1036-1039, 2010.

42. Nicol I, Boye T, Carsuzaa F, et al: Post-transplant plasmablastic lymphoma of the skin. Br J Dermatol 149: 889-891, 2003.

43. Ustun C, Reid-Nicholson M, Nayak-Kapoor A, et al: Plasmablastic lymphoma: CNS involvement, coexistence of other malignancies, possible viral etiology, and dismal outcome. Ann Hematol 88: 351-358, 2009.

44. Pruneri G, Graziadei G, Ermellino L, Baldini L, Neri A and Buffa R: Plasmablastic lymphoma of the stomach. A case report. Haematologica 83: 87-89, 1998.

45. Kravetz JD, Rose MG, Payne-Blackman S and Federman DG: Plasmablastic lymphoma presenting as an arm mass in an individual negative for human immunodeficiency virus: a case report. Clin Lymphoma Myeloma 6: 493-495, 2006.
46. Dasanu CA, Bauer F, Codreanu I, Padmanabhan $P$ and Rampurwala M: Plasmablastic haemato-lymphoid neoplasm with a complex genetic signature of Burkitt lymphoma responding to bortezomib. Hematol Oncol 31: 164-166, 2013.

47. Miller DV, Mookadam F, Mookadam M, Edwards WD and Macon WR: Primary cardiac plasmablastic (diffuse large B-cell) lymphoma mimicking left ventricular aneurysm with mural thrombus. Cardiovasc Pathol 16: 111-114, 2007.

48. Mondal SK, Bera H, Biswas PK and Mallick MG: High-grade plasmablastic neoplasm of humerus in an HIV-negative patient, which was indeterminate between plasmablastic lymphoma and plasmablastic myeloma. J Cancer Res Ther 7: 214-216, 2011.

49. Black CL, Foster-Smith E, Lewis ID, Faull RJ and Sidhu SK: Post-transplant plasmablastic lymphoma of the skin. Australas J Dermatol 54: 277-282, 2013.

50. Ojanguren J, Collazos J, Martínez C, Alvarez J and Mayo J: Epstein-Barr virus-related plasmablastic lymphomas arising from long-standing sacrococcygeal cysts in immunosuppressed patients. AIDS 17: 1582-1584, 2003

51. Montes-Moreno S, Gonzalez-Medina AR, Rodriguez-Pinilla SM et al: Aggressive large B-cell lymphoma with plasma cell differentiation: immunohistochemical characterization of plasmablastic lymphoma and diffuse large B-cell lymphoma with partial plasmablastic phenotype. Haematologica 95: 1342-1349, 2010.

52. Saba NS, Dang D, Saba J, et al: Bortezomib in plasmablastic lymphoma: a case report and review of the literature. Onkologie 36: 287-291, 2013.

53. Robak T, Urbańska-Ryś H, Strzelecka B, et al: Plasmablastic lymphoma in a patient with chronic lymphocytic leukemia heavily pretreated with cladribine (2-CdA): an unusual variant of Richter's syndrome. Eur J Haematol 67: 322-327, 2001.

54. Castillo JJ, Winer ES, Stachurski D, et al: HIV-negative plasmablastic lymphoma: not in the mouth. Clin Lymphoma Myeloma Leuk 11: 185-189, 2011.

55. Castillo JJ and Reagan JL: Plasmablastic lymphoma: a systematic review. Sci World J 11: 687-696, 2011. 